\title{
von Willebrand Disease (vWD)
}

\section{Background}

1. Definition

- Bleeding disorder characterized by mutations that lead to an impairment in synthesis or function of von Willebrand Factor (vWF)

2. General information

- Most common inherited bleeding disorder

- Most commonly inherited but acquired forms do exist

○ Types: 1, 2, 3, and acquired vWD

\section{Pathophysiology}

1. Pathology of disease

$\circ \quad$ von Willebrand Factor (vWF)

- Large protein synthesized in endothelial cells and megakaryocytes

- Aids in hemostasis by:

- Binding to platelets and subendothelial components to promote platelet adhesion and aggregation

- Serves as a carrier molecule for Factor VIII and thus increases its half-life

- Multiple types of vWD due to:

- Decreased levels of vWF (quantitative), or

- Altered structure leading to decreased binding (qualitative)

- Type 1

- Quantitative deficiency of vWF

- Autosomal dominant mutations, most of which are unknown

- Accounts for $70 \%$ of patients with vWD

- Symptoms range from asymptomatic to moderately severe bleeding

- Type 2

- Qualitative deficiency of vWF

- Multiple subtypes with well known mutations

- Mostly autosomal dominant with one autosomal recessive subtype

- Accounts for $20 \%$ of patients with vWD

- Subtype $2 \mathrm{~N}$ can be confused with Hemophilia A due to concomitant decrease in Factor VIII levels

- Affected patients usually have moderate to severe bleeding

- Type 3

- Severe quantitative deficiency of $\mathrm{vWF}$

- Autosomal recessive with well known mutations

- Rare disease affecting about 1 per million patients

- Marked decrease or absence of vWF

- Can also be confused with Hemophilia A as they also have decreased Factor VIII levels

- Affected patients present with severe bleeding 
- Acquired von Willebrand Disease (AvWD)

- Caused by a broad range of disease states and some drugs

- Associated diseases

- Lymphoproliferative disorders

- Myeloproliferative disorders

- Hypothyroidism

- Multiple myeloma

- Autoimmune disorders such as

- Systemic lupus erythematosus

- Uremia

- Drugs

- Valproic acid

- Griseofulvin

- Ciprofloxacin

2. Incidence and prevalence

- Affects up to $1 \%$ of population

$\circ$ Only $5 \%$ of those affected will be symptomatic

3. Risk factors

- Family Hx of vWD or personal Hx of the above disorders known to cause AvWD

4. Morbidity

- Anemia

- Iron deficiency

- Arthropathies

5. Mortality

- Rarely causes death and is usually associated with bleeding from significant trauma

\section{Diagnostics}

1. History

- Personal or family Hx of:

- Bleeding problem requiring medical attention

- Prolonged bleeding after surgery, dental work, or trauma

- Easy bruising or bruises with lumps

- Skin bleeding or mucosal bleeding

- Nasal, oral, GI, or uterine

- Liver dz, kidney dz, bone marrow disorder, or low platelets

- Taking anticoagulants or antiplatelet medications

2. Physical exam

- Look for following forms of blood extravasation into tissues with red, purple, green, yellow, brown coloration spectrum

- Petechiae

- Pinpoint areas $<2 \mathrm{~mm}$ in diameter

- Ecchymoses

- Areas $>1 \mathrm{~cm}$ in diameter

- Hematomas

- Large collection of blood in subcutaneous tissue, similar to ecchymosis but with palpable lump 
- Look for:

- Conjunctival pallor which may suggest underlying anemia

- Evidence of other causes such as

- Stigmata of liver $\mathrm{dz}$

- Uterine fibroids

- Splenomegaly

3. Diagnostic tests

- Initial laboratory evaluation

- $\mathrm{CBC}$

- Usually normal but may show anemia if significant bleeding has occurred

- Platelet count should be normal

- $\mathrm{PT}$

- Should be normal

- PTT

- May be normal or slightly prolonged

- 1:1 mixing study will show correction of PTT

- $\mathrm{TT}$

- Should be normal

- Fibrinogen

- Should be normal

- If there is a strong $\mathrm{Hx}$ of mucosal bleeding consider adding vWD assay below with initial studies

- There are likely to be no abnormalities in above studies or only a slightly elevated PTT

- If there is an isolated PTT elevation that corrects on a 1:1 mixing study, do vWD assay below [SOR C]

- vWD Assay [SOR B]

- vWF Antigen (vWF:Ag)

- vWF Ristocetin Cofactor activity (vWF:RCo)

- Factor VIII_activity level

- If any of these studies are abnormally low, hematology referral is indicated for complete evaluation

\section{Differential Diagnosis}

1. Factor VIII deficiency (Hemophilia A)

- X-linked, usually affecting only males

- Causes deep tissue, muscle, joint, and GI bleeding

- Difficult to distinguish from vWD Type 2N due to low Factor VIII levels in both

2. Factor IX deficiency (Hemophilia B)

- Causes deep tissue, muscle, joint, and GI bleeding

- Labs will reveal low Factor IX levels, not seen in vWD

\section{Factor XI deficiency}

- Spontaneous bleeding uncommon

- Patients will have a prolonged PTT that corrects on 1:1 mixing study, but Factor XI activity levels will be reduced, unlike vWD

- vWD assays should be normal 


\section{Platelet function defects}

- Inherited forms very rare

- Acquired forms due to uremia, liver dz, myeloproliferative disorders, and cardiopulmonary bypass machines

- Platelet count may be low or normal

- PT/PTT will be normal

5. Anti-platelet drug ingestion

- History of anti-platelet drug use with isolated platelet dysfunction as described above

\section{Therapeutics}

1. Acute treatment

○ Minor bleeding

- Desmopressin (DDAVP) nasal or IV [SOR B]

- IV: $0.3 \mathrm{mcg} / \mathrm{kg}$ by slow infusion

- Intranasal $(1.5 \mathrm{mg} / \mathrm{mL})$

- $\quad<50 \mathrm{~kg}: 150 \mathrm{mcg}$ (1 spray)

○ $\quad>50 \mathrm{~kg}: 300 \mathrm{mcg}$ (1 spray each nostril)

- If response inadequate then use $\mathrm{vWF}$ concentrate, $40-80 \mathrm{IU} / \mathrm{kg}$ loading followed by 40-60 IU/kg Q8-12 hours [SOR C]

- Major bleeding

- Admit to hospital with:

- Hematologist

- Surgeon

- 24-hour lab services where vWD assays are available [SOR C]

- Treatment plan should be based on getting Factor VIII activity level and vWF:RCo level > $100 \mathrm{IU} / \mathrm{dL}$ using DDAVP or vWF concentrate at above dosing [SOR B]

- Transfuse red blood cells and platelets as indicated

\section{Long-term care}

- Trial of DDAVP with measured vWF:RCo activity and Factor VIII activity responses should be performed in non-acute setting [SOR B]

- Counsel to avoid aspirin and NSAIDs [SOR C]

- Pts >2 yo should be vaccinated against Hepatitis A and B [SOR C]

- Long term prophylaxis is currently under investigation

- Minor Surgery Prophylaxis

- DDAVP if patient has documented adequate response or vWF concentrate to keep activity levels > $30 \mathrm{IU} / \mathrm{dL}$ for 1-5 days [SOR B]

- Major Surgery Prophylaxis

- DDAVP if patient has documented adequate response or vWF concentrate to achieve activity level $>100 \mathrm{IU} / \mathrm{dL}$ and then $>50 \mathrm{IU} / \mathrm{dL}$ for 7-10 days [SOR B]

- Menorrhagia in Women

- Full gynecological evaluation should be completed prior to starting therapy [SOR C]

- Women who do not desire pregnancy should be given combined oral contraceptive pills (OCPs) as 1st-line therapy [SOR B] 
- Women who do not desire pregnancy and are candidates for intrauterine devices should receive a levonorgestrel intrauterine system as second line therapy [SOR B]

- For those women who desire pregnancy, DDAVP or vWF concentrate may be used [SOR C]

- Management during Pregnancy and Delivery

- Referral should be made to a high risk obstetrician as well as hematology

- DDAVP or vWF concentrate should be used prior to invasive procedures [SOR C]

- Factor VIII and VWF:RCo levels should be > $50 \mathrm{IU} / \mathrm{dL}$ prior to delivery and maintained for 3-5 days [SOR C]

- Regional anesthesia may be used if activity levels are > $50 \mathrm{IU} / \mathrm{dL}$ [SOR C]

- Patients should have frequent follow-up during the first 3 weeks postpartum as VWF levels return to baseline

\section{Follow-Up}

1. Return to office

- Early follow-up during initial diagnosis

- Routine follow-up is adequate for patients with an established diagnosis who are stable

2. Refer to specialist

- Refer to hematologist when vWD assays are abnormal for complete diagnosis with classification

3. Admit to hospital

- For acute bleeding episodes

\section{Prognosis}

1. Good prognosis with most patients being asymptomatic and never diagnosed

\section{Prevention}

1.Patients should have the opportunity to speak with a genetic counselor [SOR C]

\section{Patient Education}

1. Education materials from National Heart Lung and Blood Institute - http://www.nhlbi.nih.gov/health/dci/Diseases/vWD/vWD_WhatIs.html

2. Clinical Practice Guidelines for Von Willebrand Disease

$\circ$ http://www.nhlbi.nih.gov/guidelines/vwd/

\section{References}

1. Rodeghiero, F, Castaman, G, Dini, E. Epidemiological investigation of the prevalence of von Willebrand's disease. Blood 1987; 69:454

2. Mannucci, PM, Bloom, AL, Larrieu, MJ, et al. Atherosclerosis and von Willebrand factor. I. Prevalence of severe von Willebrand's disease in western Europe and Israel. Br J Haematol 1984; 57:163

3. Veyradier, A, Jenkins, CS, Fressinaud, E, Meyer, D. Acquired von Willebrand syndrome: From pathophysiology to management. Thromb Haemost 2000; $84: 175$ 
4. Simone, JV, Cornet, JA, Abildgaard, CF. Acquired von Willebrand's syndrome in systemic lupus erythematosus. Blood 1968; 31:806

5. Wautier, JL, Levy-Toledano, S, Caen, JP. Acquired von Willebrand's syndrome and thrombopathy in a patient with chronic lymphocytic leukaemia. Scand J Haematol 1976; 16:128

6. National Institutes of Health, National Heart, Lung, and Blood Institute (NHLBI). The diagnosis, evaluation, and management of von Willebrand disease. Bethesda (MD): U.S. Department of Health and Human Services; 2007

7. Rodeghiero F, Castaman G, Dini E. Epidemiological investigation of the prevalence of von Willebrand's disease. Blood 1987 Feb;69(2):454-459

8. Gill JC, Endres-Brooks J, Bauer PJ, Marks WJ Jr, Montgomery RR. The effect of ABO blood group on the diagnosis of von Willebrand disease. Blood 1987 Jun;69(6):1691-1695

9. Favaloro EJ, Bonar R, Kershaw G, Sioufi J, Hertzberg M, Street A, Lloyd J, Marsden Laboratory diagnosis of von Willebrand's disorder: quality and diagnostic improvements driven by peer review in a multilaboratory test process. Haemophilia 2004 May;10(3):232-242

10. Favaloro EJ, Thom J, Baker R, Australasian Society for Thrombosis and Haemostasis (ASTH) Emerging Technology Group. Assessment of current diagnostic practice and efficacy in testing for von Willebrand's disorder: results from the second Australasian multi-laboratory survey. Blood Coagul Fibrinolysis 2000 Dec;11(8):729-737

11. Castaman G, Lattuada A, Mannucci PM, Rodeghiero F. Factor VIII:C increases after desmopressin in a subgroup of patients with autosomal recessive severe von Willebrand disease. Br J Haematol 1995 Jan;89(1):147-151

12. Castaman G, Rodeghiero F. Desmopressin and type II B von Willebrand disease. Haemophilia 1996 Apr;2(2):73-77

13. de la Fuente B, Kasper CK, Rickles FR, Hoyer LW. Response of patients with mild and moderate hemophilia A and von Willebrand's disease to treatment with desmopressin. Ann Intern Med 1985 Jul;103(1):6-14

14. Rodeghiero F, Castaman G, Di Bona E, Ruggeri M, Lombardi R, Mannucci PM. Hyper-responsiveness to DDAVP for patients with type I von Willebrand's disease and normal intra-platelet von Willebrand factor. Eur J Haematol 1988 Feb;40(2):163-167

15. Mariana G, Ciavarella N, Mazzucconi MG, Antoncecchi S, Solinas S, Ranieri P, Pettini P, Agrestini F, Mandelli F. Evaluation of the effectiveness of DDAVP in surgery and in bleeding episodes in haemophilia and von Willebrand's disease. A study on 43 patients. Clin Lab Haematol 1984;6(3):229-238

16. Nitu-Whalley IC, Griffioen A, Harrington C, Lee CA. Retrospective review of the management of elective surgery with desmopressin and clotting factor concentrates in patients with von Willebrand disease. Am J Hematol 2001 Apr;66(4):280-284

17. Lillicrap D, Poon MC, Walker I, Xie F, Schwartz BA. Efficacy and safety of the factor VIII/von Willebrand factor concentrate, Haemate-P/Humate-P: ristocetin cofactor unit dosing in patients with von Willebrand disease. Thromb Haemost $2002 \mathrm{Feb} ; 87(2): 224-230$

18. Kreuz W, Mentzer D, Becker S, Scharrer I, Kornhuber B. Haemate-P® in children with von Willebrand's disease. Haemostasis 1994 Sep; 24(5):304-310 
19. Dobrkovska A, Krzensk U, Chediak JR. Pharmacokinetics, efficacy and safety of Humate-P® in von Willebrand disease. Haemophilia 1998;(4 Suppl 3):33-39

20. Hanna WT, Bona RD, Zimmerman CE, Carta CA, Hebert GZ, Rickles FR. The use of intermediate and high purity factor VIII products in the treatment of von Willebrand disease. Thromb Haemost 1994 Feb;71(2):173-179

21. Lubetsky A, Schulman S, Varon D, Martinowitz U, Kenet G, Gitel S, Inbal A. Safety and efficacy of continuous infusion of a combined factor VIII-von Willebrand factor (vWF) concentrate (Haemate-P®) in patients with von Willebrand disease. Thromb Haemost 1999 Feb;81(2): 229-233

22. Michiels JJ, Berneman ZN, van der Planken M, Schroyens W, Budde U, van Vliet $\mathrm{HH}$. Bleeding prophylaxis for major surgery in patients with type 2 von Willebrand disease with an intermediate purity factor VIII-von Willebrand factor concentrate (Haemate-P). Blood Coagul Fibrinolysis 2004 Jun;15(4):323-330

23. Thompson AR, Gill JC, Ewenstein BM, Mueller-Velten G, Schwartz BA, Humate-P® Study Group. Successful treatment for patients with von Willebrand disease undergoing urgent surgery using factor VIII/VWF concentrate (Humate$P()$. Haemophilia 2004 Jan;10(1):42-51

24. Scharrer I, Vigh T, Aygoren-Pürsün E. Experience with Haemate-P in von Willebrand's disease in adults. Haemostasis 1994 Sep;24(5):298-303

25. Gill JC, Ewenstein BM, Thompson AR, Mueller-Velten G, Schwartz BA, Humate-P® Study Group. Successful treatment of urgent bleeding in von Willebrand disease with factor VIII/VWF concentrate (Humate-P®): use of the ristocetin cofactor assay (VWF:RCo) to measure potency and to guide therapy. Haemophilia 2003 Nov;9(6):688-695

26. Mannucci PM, Lombardi R, Bader R, Vianello L, Federici AB, Solinas S, Mazzucconi MG, Mariani G. Heterogeneity of type I von Willebrand disease: evidence for a subgroup with an abnormal von Willebrand factor. Blood 1985 Oct;66(4):796-802

27. Federici AB, Mazurier C, Berntorp E, Lee CA, Scharrer I, Goudemand J, Lethagen S, Nitu I, Ludwig G, Hilbert L, et al. Biologic response to desmopressin in patients with severe type 1 and type 2 von Willebrand disease: results of a multicenter European study. Blood 2004 Mar;103(6):2032-2038

28. Mannucci PM, Canciani MT, Rota L, Donovan BS. Response of factor VIII/von Willebrand factor to DDAVP in healthy subjects and patients with haemophilia A and von Willebrand's disease. Br J Haematol 1981 Feb;47(2):283-293

29. Rodeghiero F, Castaman G, Di Bona E, Ruggeri M. Consistency of responses to repeated DDAVP infusions in patients with von Willebrand's disease and hemophilia A. Blood 1989 Nov;74(6):1997-2000

30. Barbui T, Rodeghiero F, Dini E. The aspirin tolerance test in von Willebrand's disease. Thromb Haemost 1977 Aug;38(2):510-513

31. Rosenstein R, Zacharski LR. The diagnostic value of the aspirin tolerance test. Thromb Res 1979;16(1-2):219-230

32. Stuart MJ, Miller ML, Davey FR, Wolk JA. The post-aspirin bleeding time: a screening test for evaluating haemostatic disorders. Br J Haematol 1979 Dec;43(4):649-659.

33. National Hemophilia Foundation (NHF). 2001. MASAC Recommendation 128. Recommendations for hepatitis A and B immunization of individuals with bleeding disorders Available at: 
http://www.hemophilia.org/NHFWeb/MainPgs/MainNHF.aspx?menuid=57\&;con tentid $=240$

34. Revel-Vilk S, Schmugge M, Carcao MD, Blanchette P, Rand ML, Blanchette VS. Desmopressin (DDAVP) responsiveness in children with von Willebrand disease. J Pediatr Hematol Oncol 2003 Nov;25(11):874-879

35. Federici AB, Sacco R, Stabile F, Carpenedo M, Zingaro E, Mannucci PM. Optimising local therapy during oral surgery in patients with von Willebrand disease: effective results from a retrospective analysis of 63 cases. Haemophilia 2000 Mar;6(2):71-77

36. Chuong CJ, Brenner PF. Management of abnormal uterine bleeding. Am J Obstet Gynecol 1996 Sep;175(3 Pt 2):787-792

37. Foster PA. The reproductive health of women with von Willebrand Disease unresponsive to DDAVP: results of an international survey. On behalf of the Subcommittee on von Willebrand Factor of the Scientific and Standardization Committee of the ISTH. Thromb Haemost 1995 Aug;74(2):784-790

38. Kingman CE, Kadir RA, Lee CA, Economides DL. The use of levonorgestrelreleasing intrauterine system for treatment of menorrhagia in women with inherited bleeding disorders. BJOG 2004 Dec;111(12):1425-1428

39. Kadir RA. Women and inherited bleeding disorders: pregnancy and delivery. Semin Hematol 1999 Jul;36(3 Suppl 4):28-35

40. Kouides PA. Obstetric and gynaecological aspects of von Willebrand disease. Best Pract Res Clin Haematol 2001 Jun;14(2):381-399

41. Pasi KJ, Collins PW, Keeling DM, Brown SA, Cumming AM, Dolan GC, Hay CR, Hill FG, Laffan M, Peake IR. Management of von Willebrand disease: a guideline from the UK Haemophilia Centre Doctors' Organization. Haemophilia 2004 May;10(3):218-231

42. Mannucci PM. Treatment of von Willebrand's disease. N Engl J Med 2004 Aug;351(7):683-694

43. Greer IA, Lowe GD, Walker JJ, Forbes CD. Haemorrhagic problems in obstetrics and gynaecology in patients with congenital coagulopathies. Br J Obstet Gynaecol 1991 Sep;98(9):909-918

44. Kadir RA, Lee CA, Sabin CA, Pollard D, Economides DL. Pregnancy in women with von Willebrand's disease or factor XI deficiency. Br J Obstet Gynaecol 1998 Mar;105(3):314-321

Author: William Fieldsmith, MD, Baylor COM, TX

Editor: Wail Malaty, MD, University of North Carolina FPRP 